\title{
Research on Accounting Treatment and Information Presentation of Enterprise Data Assets
}

\author{
An Wang \\ Chong Qing College Of Architecture And Technology 401331
}

\begin{abstract}
In the process of rapid development of big data technology, the digital technology revolution is developing faster and faster. In the context of big data, the data resources of enterprises have been equipped to become data assets. The corporate financial accounting system requires effective accounting treatment and information presentation of data assets. This is a problem that must be addressed in the current corporate development process. This article researches and analyzes the accounting treatment of enterprise data assets and the related content of information presentation. The author also discussed the specific characteristics of data assets in the course of enterprise operation, and how to strengthen the classification research work of data assets. This can improve the effectiveness of the data asset information presentation model, and provide a reference for similar enterprise data asset business and related information disclosure. This is also conducive to give full play to the value discovery function of accounting information in the development process of the enterprise, and reduce the problem of asymmetry of internal and external information.
\end{abstract}

\section{Introduction}

Internet companies are developing relatively fast, and their scale of development is getting bigger and bigger. In this process, the effective application of data resources plays a vital role. Obviously, data resources have developed in the Internet industry. In addition, the publicly disclosed information of companies engaged in data mining shows that many non-Internet industries have begun to fully apply professional data mining technologies, which can effectively collect massive data resources. Public documents such as corporate financial reports and performance forecasts also show that the use of data mining technology can improve the quality of business to a certain extent. This is conducive to enhancing the enterprise's ability to prevent and control risks, thereby improving the economic benefits of the enterprise. In addition, in the process of continuous development of data transaction business, the full application of big data transaction platforms can to a certain extent encourage enterprises to further use data resources. In this process, we need to make it clear that data resources already have the value of data assets. This requires the use of effective principles and systems to fully grasp issues such as enterprise data asset accounting treatment and information presentation. This can enable enterprises to give full play to the positive role of data assets and promote the development of enterprises [1].

\section{Data Asset Overview}

Data refers to raw materials that have not been processed for objective things. Big data refers to information resources that can effectively reflect the movement and state changes of the physical world and the spiritual world [2]. In the development of big data technology, data itself is the carrier of information, including symbols, characters, numbers, languages, images, videos, etc. From this perspective, data and information are inseparable. In the process of continuous development of data resources, it already has certain data asset conditions. This is mainly because data resources can create economic benefits for enterprises to a certain extent. For example, data assets such as documents and electronic data in the development of an enterprise can produce value for the enterprise. However, some researchers believe that data resources cannot be used as descriptive information for other assets, because data with a certain value in the data resource itself is an asset. Therefore, data assets can be regarded as smart assets that can improve process efficiency and endow products with new functions in business models.

In the process of defining data assets, we need to show the uniqueness of data assets. Data assets have the following characteristics. Firstly, the form of data. The data asset is a data resource with a certain value. The form of digitization is not only the main feature of data assets, but also the outstanding feature that distinguishes them effectively from other assets. When analyzing and researching data assets, we must be clear about this characteristic. Secondly, data assets are highly identifiable. In the process of enterprise development, data assets are relatively less dependent on the business model of the enterprise itself, which can ensure its transaction value to external entities of the enterprise. In the process of data resource mining and analysis, it can affect the 
management and decision-making of enterprises to a certain extent. This shows that the data assets within the enterprise can provide certain services for enterprise decision-making, which has a certain connection with the business model of the enterprise. If it is analyzed as asset data, it can be determined that it can bring economic value to the enterprise. This value is clearly distinguished from the economic value generated by the enterprise in the course of its operation. This shows that data assets are separated from the business model of the company and are assets that can generate value. As a result, companies can not only effectively sort and analyze data resources to separate data assets, but also sell or transfer all or part of their data assets. This shows that data assets are highly identifiable and belong to identifiable assets. Thirdly, nonmonetary. In the process of defining the concept of data assets, we must emphasize the non-monetary nature of data assets. This is mainly to distinguish data assets from the current legal digital currency. Digital currency generally refers to virtual currency based on blockchain technology, which is quite different from the concept of data assets. When defining the concept of data assets, we need to highlight the non-monetary nature of data assets. We should try our best to distinguish it effectively from concepts such as legal digital currency and digital assets. Only in this way can the specific characteristics of data assets be clarified. After analyzing the characteristics of data assets, we can determine that data assets are identifiable non-monetary assets with a digital form that are owned or controlled by enterprises [3].

\section{Account Setting of Data Assets}

In the process of accounting for data assets, we must carry out account setting work. We can proceed from the following aspects to ensure the validity and rationality of the subject setting.

Firstly, the rationality of the first-level subject setting. When researchers studied the subject setting of data assets, they found that the relevant research conclusions were not uniform. Because data assets themselves are intangible assets, some researchers suggest setting data assets as a secondary subject under the intangible asset account, and at the same time explain and explain the information of data assets in detail in the notes to the financial statements. However, because there are certain differences between the accounting system of data assets and intangible assets, it has strong uniqueness in itself. Some researchers believe that the traditional intangible asset accounting system cannot adapt to the secondary account accounting work of data assets, and it is necessary to directly set the primary account data asset list. By analyzing the characteristics of data assets and accounting requirements, it is more reasonable to classify data asset subjects as first-level subjects when designing subjects. This is mainly because the data asset itself has the three characteristics of restoring non-monetary, identifiable, and digital form. It is similar to the intangible assets of the accounting system. However, there are still some differences. For example, data assets are illiquid, data, and non-intellectual. (1) Illiquidity refers to data assets including self-use data assets and transaction data assets. In the big data environment, the data update speed is getting faster and faster. The value of data resources is determined based on the volume of data. This results in the data asset application process with a service life of more than one year before the data resource volume accumulation process can be completed. When analyzing data assets, they themselves are non-current assets. However, during its useful life, there are certain differences in the accounting treatment of data assets for different purposes. For self-use data assets, information users are more concerned about the relationship between economic benefits and the cost of acquiring data assets. The value of data assets is mainly reflected in the price paid in the process of acquiring data assets. At the same time, we must not only comprehensively consider the availability and timeliness of data resources, but also carry out amortization of data assets according to appropriate methods and carry out effective impairment tests. Only in this way can we accurately grasp the value of data assets. For transaction data assets, information users are concerned about the economic benefits obtained from data asset transactions. In this case, the value of data assets will fluctuate as the market changes. After the data asset transaction is concluded, it will not affect the company's subsequent transactions. When accounting for this type of data assets, we need to use fair value measurement to be able to reflect economic benefits. Data assets have strong illiquidity. We need to amortize data assets for self-use, while transaction data assets need to be accounted for using the fair value model. This is obviously different from intangible assets. (2) The main performance of data is that the data asset itself is displayed in the form of data, and the data itself is the unique performance of the data asset. When acquiring data assets, the main method is to register an account, key or electronic document. The data assets controlled by the enterprise are not transferred in and out, but all data resources are sold. This shows that data assets have strong data nature. According to the characteristics of data, it can be determined that data assets can be measured. We can use specialized technologies or algorithms to complete data collection, and use network storage, transmission, and transactions to achieve the purpose of obtaining economic benefits. When analyzing data assets, they belong to information products, and information products can be digitized. It can be directly used as a transaction object for online transactions in the Internet. This feature also shows a clear difference from the intangible assets in the current accounting system [4]. (3) Non-intellectual property rights. At present, intangible assets mainly include technical and non-technical assets. Technical intangible assets have relatively high requirements for intellectual property patent rights. Data assets are comparable to technical intangible assets, but data assets are not intellectual property intangible assets. Data assets can bring economic value to enterprises, but they do not only depend on the business model of the enterprise. This shows that the data resources of data assets have knowledge potential, but they have not formed the knowledge results that enterprises need. Therefore, data assets do not meet the intellectual property conditions. Analyzing data assets on the other hand, big data itself is 
the asset of the controller, and big data cannot be accurately classified into any type of property rights such as property rights, quasi-property rights, and intellectual property rights. With the continuous development of information technology, a new type of property rights object, namely information property, will appear. This shows that there are certain differences in the rights of data assets and intellectual property rights. Therefore, we cannot use the current accounting treatment of intangible assets for processing. We need to separate data assets as first-level subjects, carry out accounting processing and information presentation. Only in this way can it be ensured that the relevant information of enterprise data assets can be effectively transmitted and the effectiveness of information presentation can be improved [5].

Secondly, the content of secondary subjects. In the process of data asset application, it itself can provide a certain reference for corporate decision-making, and at the same time it can conduct external transactions and information sharing. However, data assets can be repeatedly mined, which results in their data assets being able to have both their own applications and external transactions. In different processes, the accounting treatment of data assets is quite different. We need to set up secondary subjects according to the specific content of accounting processing. Table 1 shows the specific secondary subject setting framework.

Table1. A Framework for Setting Secondary Subjects in the Accounting Treatment of Enterprise Data Assets

\begin{tabular}{|c|c|c|}
\hline Subject & Subject Setting & Details \\
\hline $\begin{array}{c}\text { Level } 1 \\
\text { Subjects }\end{array}$ & Data Assets & Corporate Illiquid Assets \\
\hline \multirow{3}{*}{$\begin{array}{l}\text { Level } 2 \\
\text { Subjects }\end{array}$} & Self-use Data Assets & $\begin{array}{c}\text { The Data Assets of the } \\
\text { Enterprise in its Own } \\
\text { Business }\end{array}$ \\
\hline & $\begin{array}{c}\text { Transaction Data } \\
\text { Assets }\end{array}$ & $\begin{array}{c}\text { Data Assets Used by } \\
\text { Enterprises for } \\
\text { Transactions }\end{array}$ \\
\hline & $\begin{array}{c}\text { Changes in Fair Value } \\
\text { of Transaction Data } \\
\text { Assets }\end{array}$ & $\begin{array}{l}\text { Reflect the Difference } \\
\text { Between the Fair Value } \\
\text { and Book Value of Data } \\
\text { Assets in the Process of } \\
\text { Corporate Balance Sheet } \\
\text { Transactions }\end{array}$ \\
\hline
\end{tabular}

\section{Information Presentation of Data Assets}

After the accounting treatment of enterprise data assets, the data assets need to be listed. We need to supplement the corresponding data assets in the notes to the financial report. Especially for listed companies, it also needs to ensure that the relevant information presentation of data assets is reliable and complete according to the specific needs of information users. In annual reports and other periodic reports, the textual information must be accurate.
We can start the presentation of corporate data assets from the following aspects.

Firstly, data assets can help companies complete financial statements and notes. In this link, data asset items should be set up in the non-current assets part of the balance sheet. Moreover, the company must also specify the data asset life and amortization method confirmed during the accounting period in the financial statements. Besides, companies need to mark the data asset impairment test methods and related results in the accounting process. This can ensure that the fair value evaluation method of data asset transaction assets can be displayed in detail. In addition, the basis for determining the proportion of newly recognized data assets for self-use and transaction purposes needs to be elaborated in the notes to the financial statements.

Secondly, data assets can be included in regular reports in the textual information disclosure specifications. If only using financial statement data to show information about data assets to information users, it will lead to the problem of asymmetry in the internal and external information obtained by information users. This requires companies to ensure the comprehensiveness of textual information disclosure in relevant financial reports. In the existing financial reports, listed companies need to strengthen the core competitiveness analysis of the company's main business and future development prospects and other information disclosure. Enterprises should use this information to reflect the specific content of data asset information. Only in this way can it reflect the company's positioning and evaluation of its own asset data assets. In consequence, only when asset information needs to be disclosed in corporate annual reports and other periodic reports can it reflect the positive effects of data assets on corporate development. We can proceed from three aspects in terms of the disclosure of data assets. (1) The technical support of the enterprise in the development process. In the era of big data, users of enterprise internal information can use big data mining technology to obtain corresponding information. The efficiency of data asset mining is closely related to the level of big data mining technology. Therefore, in the development process of different enterprises, there are also certain differences in the degree of data resource control and the efficiency of its use. In the process of enterprise development, valuable data information obtained from large amounts of data is very important. Therefore, companies must improve their data resource acquisition, mining and analysis capabilities. (2) The enterprise needs to strengthen talent training and technology introduction, and the management needs to explain in detail the technical issues that information users are concerned about in the financial report. This can meet the needs of information users for corporate data assets. At present, the larger and faster the data resources of enterprises are in the process of continuous development of big data technology, this can make the data resources of enterprises more and more abundant. This can improve the management decision-making level of the enterprise to a certain extent. Enterprises need to pay attention to the full application of big data mining technology. Only in this way can companies obtain more objective and comprehensive data and prevent the management from 
conducting management decision-making work based on intuitive judgment. In the process of applying big data mining technology, companies need to have a clear understanding and mastery of the current scale of data resources. Companies can help external information users to have a deep understanding of the company's own data assets. Hence, when reporting information on corporate data assets, we need to disclose information such as the specific resource volume types of data assets. Only in this way can it reflect the economic value created by the enterprise under the cost of its own data assets [6]. (3) Enterprises must show relevant economic benefits. The rapid development of enterprises and the full application of data assets can improve the economic benefits of enterprises. This is also the key content that internal and external information users pay more attention to. For the company's own data assets, the economic benefits generated may be indirect, and companies need to use words to reflect the economic benefits generated by data assets. For example, banks can analyze customer satisfaction of investment portfolio design by integrating customer data resources and complete credit level assessments to grasp the risk of non-performing loans. Under the influence of these relevant data, data assets can help banks analyze the economic benefits that can be obtained.

\section{Conclusion}

In summary, in the process of the continuous development of the big data era, the digital economy has risen rapidly, and the concept of data assets has attracted more and more attention. However, in the current process of data asset development, accounting treatment and information presentation mechanisms are not perfect. This will affect the security and rationality of data assets to a certain extent. Therefore, companies need to strengthen the analysis and research work of data asset accounting and information presentation in the era of big data, and to find out the various characteristics of data assets. Only in this way can the data assets be effectively divided into subjects, and the accounting treatment and information presentation of the data assets can be carried out smoothly and orderly. In addition, companies can complete the disclosure of information on the technical status of data assets and the scale of data resources in the financial report of the data asset enterprise value positioning. In the context of the rapid development of digital technology, enterprises are increasingly applying data assets. Therefore, companies need to strengthen the standardized management of data asset accounting and information presentation. Proposing related methods for data asset accounting and information presentation based on the characteristics of data assets can strengthen in-depth research on this issue. Meanwhile, companies can have a deeper understanding of the accounting attributes of data assets. The scientific design of the accounting treatment principles and methods of data assets is conducive to the disclosure of relevant information about corporate data assets and ensures that investors can understand the information needs of various soft assets such as corporate data assets. This can also improve the problem of market information asymmetry to a certain extent, thereby increasing the application value of data assets.

\section{References}

1. Song Ying. Research on the Reform of Information Classification and Presentation in the Financial Statements of Enterprises - - Based on the Perspective of Financial Statement Analysis [J]. 2009.

2. Li Ranran. Research on the presentation of financial statements [D].

3. Zhang Jian. Research on the Accounting Treatment of Chinese Government Subsidies [D].

4. Li Feifei. Research on Financial Asset Information Disclosure of Chinese Listed Companies [D]. 2012.

5. Wang Yan. Research on the Accounting Presentation of Data Assets[J]. Shanxi Finance and Taxation, 2020,

6. No.493(03):38-40.

7. Zhang Junrui, Wei Yanlin, Song Xiaoyue. Research on Accounting Treatment and Information Presentation of Enterprise Data Assets[J]. Accounting and Economic Research, 2020(3). 